\title{
Dropping a line from space
}

As Nature went to press, scientists were scrambling to locate a small capsule from space now believed to be somewhere in Kazakhstan. The capsule is part of an ambitious experimental space-mail delivery system that aimed to use a 30-kilometre-long satellite tether - the longest yet. In the early hours of 25 September, the ribbon from the satellite orbiting 300 kilometres above Earth was cut and the capsule parachuted to Earth, although off-target.

The test forms part of the European Space Agency's Foton-M3 mission, which set out on its 12-day Earth-orbiting science mission on 14 September. Foton-M3 is carrying more than 40 science experiments, including the tether test, called Young Engineers' Satellite 2(YES2), $\mathrm{a} € 2.7$-million (US $\$ 3.8$-million) project involving more than 450 students. The idea was to demonstrate the feasibility of a cheap way of returning small objects to Earth from distances similar to that of the International Space Station some 330 kilometres away.

Delivering small payloads from low Earth orbits is not as easy as simply dropping them. "You don't want this object to spin around the Earth," says Francesco Emma, head of the European Space Agency's education office. The capsule, or any other payload, must slow down so that it can come out of its orbit. This can be done using a retro-rocket, but tethers are another way. "You can lower the capsule," says Emma. "When it is released it doesn't have enough energy to spin."

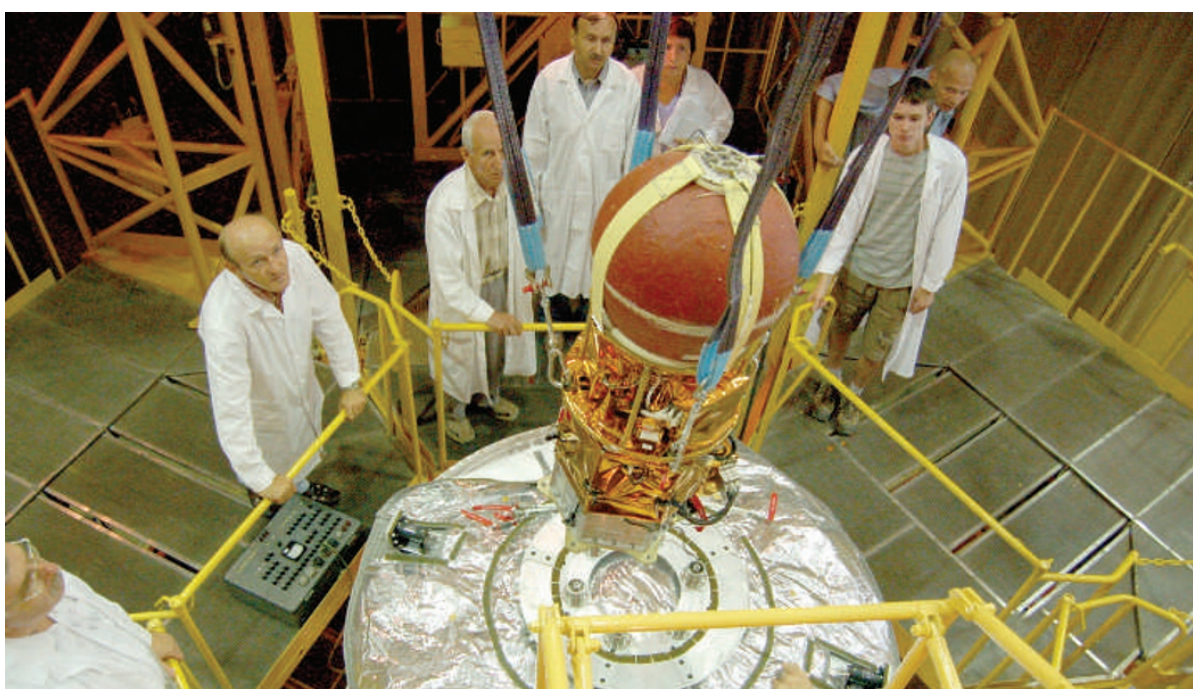

YES2, a 6-kilogram capsule (pictured), was hung from a satellite by a tether before falling to Earth.

The tether, just 0.6 millimetres thick, was made from a super-strong polyethylene fibre called Dyneema and weighed 5.5 kilograms. YES2 consisted of three parts: the 6-kilogram capsule, together with heat shield, that returned to Earth; a carrier that held the capsule in place; and a deployer, bolted to Foton-M3, that held both capsule and carrier and a spool of tether.

The capsule was deployed in two stages 3.5 kilometres of tether was released at first. After the landing location was targeted, the idea was to reel out the rest of the tether. Once the
WRIST BONES BOLSTER

HOBBIT STATUS

Ape-like wrists suggest

that Homo floresiensis was a distinct species.

www.nature.com/news

\section{Stem-cell fraudster 'is working in Thailand'}

Disgraced South Korean cloning scientist Woo Suk Hwang has set up a research base in Thailand, according to reports from South Korea last week. Science-policy officials in Thailand say they are worried about the reports, as they knew nothing about this.

Se Pil Park, a fertility expert at Cheju National University in South Korea, says Hwang and ten colleagues have gone to Thailand to carry out cloning experiments involving the transfer of human DNA into eggs from cows, pigs and other animals. The resulting embryos cannot produce viable offspring, but might result in embryonic stemcell lines that could be cultured for

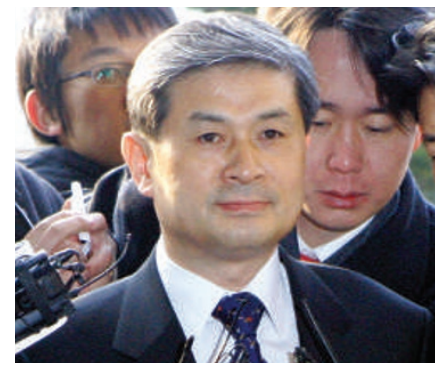

Woo Suk Hwang is said to have moved to Thailand to continue cloning.

research and for therapeutic use. In 2004, Hwang claimed to have produced embryonic stem cells by cloning human DNA using human eggs. But the data behind these claims were found to have been fabricated. Park would not disclose details of the researcher's latest work, nor where he was based.

Hwang, who remains on trial for fraud, embezzlement and violation of a bioethics law related to his discredited experiments, lost his licence to do research with human eggs. According to Park, Hwang went to Thailand to carry out interspecies cloning because he thought he would face opposition from ethicists in his home country.

In Thailand, human reproductive cloning was made illegal in 2002, but there are currently no laws regulating therapeutic cloning involving human DNA or interspecies cloning. According to Thai veterinary scientist Pradon Chatikavanij, proposed regulations on animal experimentation now before the main legislative body, the Council of State, might restrict interspecies cloning, although no decision on this has yet been made. Chatikavanij is the former head of and now a consultant for the National Research Council of Thailand, which is in charge of drafting the regulations.

Chatikavanij says the Thai government knows nothing about any research being done by Hwang in Thailand. "We should know what they are doing. We are very concerned about what is happening," he says.

David Cyranoski

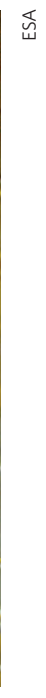

